\title{
Prácticas de valoración y gobierno corporativo: medios para la resignificación del control en las organizaciones colombianas*
}

doi:10.11144/Javeriana.cc16-40.pvgc

\section{Steven Pardo-López}

Contador público, Universidad Nacional de Colombia.

Magíster en administración, Universidad Nacional

de Colombia. Docente tiempo completo adscrito a

la carrera de contaduría pública en la Institución

Universitaria Politécnico Grancolombiano. Integrante

del grupo de investigación Economía, Derechos y

Globalización, EGD, Institución Universitaria Politécnico

Grancolombiano.

Correo electrónico: stpardoll@poligran.edu.co

\footnotetext{
* El artículo constituye el primer resultado del proyecto de investigación Estudio de impactos económicos y financieros del valor razonable en grandes empresas de Colombia: un enfoque en gobierno corporativo, adelantado con el apoyo de la Institución Universitaria Politécnico Grancolombiano e identificado bajo el código 2014-FCAEC-EDG-TC-84294.
} 
Resumen Los procesos de convergencia hacia Normas Internacionales de Información Financiera (NIIF) y de adopción del modelo de gobierno corporativo (GC) anglosajón, presentes en Colombia durante los últimos años, han contribuido a la estructuración de un contexto en el que las finanzas han aumentado su trascendencia en la definición de relaciones entre agentes organizacionales. En este sentido, el presente artículo busca aportar elementos para la comprensión del papel de las prácticas de valoración y de gobierno de empresa en la redefinición de la realidad organizacional colombiana, abordando, con especial énfasis, el valor razonable y el modelo de GC anglosajón. Se concluye que las prácticas de valoración y de GCalineadas con una visión estática de la empresa se han consolidado como referentes en Colombia por cuenta de un rol instrumental que favorece la liberalización financiera y el fortalecimiento de la relación empresa-mercados financieros, al modificar la noción de control de los acuerdos contractuales en las organizaciones e incidir en el incremento de las asimetrías de negociación en favor de los poseedores del capital financiero.

Palabras clave Gobierno corporativo; enfoques de valoración; valor razonable; control; stakeholder y mercados financieros.

\section{Códigos JEL M14; M41}

\section{Valuation Practices and Corporate Governance: Means for the Resignification of Control in Colombian Companies}

\footnotetext{
Abstract The processes involving the convergence towards the International Financial Reporting Standards (IFRS) and the adoption of the English corporate governance (CG) model present in Colombia during recent years, have contributed to the structuring of a context where finances have increased their significance in the definition of relationships between corporate agents. In this way, this article aims to contribute with elements for the
}

understanding of paper in the valuation and corporate governance practices in the redefinition of the Colombian corporate reality, with an emphasis on reasonable cost and the English CG model. We conclude that the valuation and CG practices, aligned with a static view of the company have consolidated as references in Colombia due to its vital role that favors financial liberalization and the strengthening of the relationship between the company and the financial markets. This is achieved by means of changing the notion of control of agreements in companies and influence the increase of negotiation asymmetries in favor of the owners of the financial capital.

Keywords Corporate governance; valuation approaches; reasonable cost; control; stakeholder and financial markets.

\section{Práticas de avaliação e governança corporativa: meios para a ressignificação do controlo nas organizações colombianas}

Resumo Os processos de convergência para Normas Internacionais de Informação Financeira (NIIF) e de adopção do modelo anglo-saxão de governança corporativa (GC), presentes na Colômbia durante os últimos anos, contribuíram para a estruturação de um contexto no que as finanças têm aumentado sua transcendência na definição de relacionamentos entre agentes organizacionais. Neste sentido, o presente artigo visa fornecer elementos para a compreensão do papel das práticas de avaliação e governança de empresa na redefinição da realidade organizacional colombiana, com ênfase no valor justo razoável e o modelo de GC anglo-saxão. Conclui-se que as práticas de avaliação e GC alinhadas com uma visão estática da empresa se consolidaram como referentes na Colômbia por conta de um papel instrumental que favorece a liberalização financeira e o fortalecimento da relação empresa-mercados financeiros, quando alterar a noção de controlo dos acordos contratuais nas organiza- 
ções e incidir no incremento das assimetrias de negociação em favor dos possuidores de capital financeiro.

Palavras-chave Governança corporativa; enfoques de avaliação; valor justo razoável; controle; stakeholder e mercados financeiros.

\section{Introducción}

Los cambios en los modos de producción capitalista que caracterizaron las relaciones económicas y organizacionales a lo largo del siglo XX y la primera década del siglo XXI, han sido determinantes en el desarrollo de la disciplina, la práctica y la regulación contable. La evolución desde el modelo de producción industrial hacia el modelo del capitalismo financiero y, posteriormente, hacia el modelo del capitalismo financiarizado, generó una serie de retos que incentivó la expansión de las fronteras de la contabilidad (Power, 2010).

De esta manera, a comienzos del siglo XX, la preponderancia del modelo de producción fordista amplió la importancia de la contabilidad de costos y de gestión como vía para controlar y coordinar los recursos empresariales en procura de maximizar la eficiencia del proceso productivo y mejorar los resultados de la organización. Posteriormente, el ascenso del capitalismo financiero supuso el interés de la organización por la captación masiva de recursos que le permitieran reducir el costo de financiamiento de sus actividades operativas, lo cual propicia el ascenso de la contabilidad financiera y la inclusión de algunas racionalidades y técnicas propias de las finanzas. Por último, la consolidación del capitalismo financiariza- do ha planteado un escenario en el que las actividades financieras dejan de ser un medio para apoyar las actividades productivas y se convierten en un fin para la organización; al respecto, la contabilidad ha reaccionado ampliando el margen de acción de la racionalidad y de las técnicas financieras en favor del fortalecimiento de los mercados financieros y las prácticas especulativas.

La reciente consolidación ${ }^{1}$ de la contabilidad financiera ha estado acompañada por una redefinición de los principios y las prácticas contables, que se ha valido de un marco normativo internacional, respaldado por una institucionalidad ampliamente reconocida en la Nueva Arquitectura Financiera Internacional (NAFI), para afianzar una lógica que propende por el servicio a los inversionistas y a los mercados financieros (Power, 2010).

En este sentido, la disciplina contable, comprendida como un conjunto de fundamentos teórico prácticos, ha presentado una evolución en la que la corriente económica neoclásica se ha convertido en la base de su racionalidad; de esta manera, nociones como agente racional, comportamientos hedonistas, máximo beneficio, mercados completos y en equilibrio se convirtieron en supuestos aceptados por la contabilidad y articulados para la toma de decisiones (Pardo \& Peña, 2012). Por su parte, la práctica contable, concebida como aquellas costumbres o usos que emergen conforme

\footnotetext{
1 A partir de la década de 1970, que fue el momento en el que la movilidad del capital recibió un impulso sin precedentes por cuenta de la expansión de los mercados financieros, el auge de las tecnologías de información y comunicación, TIC, y el direccionamiento macroeconómico en favor de la liberalización financiera.
} 
evoluciona la dinámica contextual (Gómez, 2011), se ha desplazado por un camino instrumentalista en el que priman las técnicas financieras que facilitan la inmediatez en los resultados. De igual modo, la regulación contable, entendida como el régimen institucionalizado para representar la realidad (Gómez, 2011), se ha decantado por un conjunto de estándares de aplicación internacional que problematizan los sistemas contables nacionales e incentivan procesos de uniformidad.

Estas transformaciones, incubadas en los países anglosajones, se han expandido por diferentes regiones del mundo a través, entre otros, del proceso de estandarización internacional mediado por el International Accounting Standards Board (IASB) y el Financial Accounting Standards Board (FASB) e instrumentalizado mediante las Normas Internacionales de Contabilidad (NIC), las Normas Internacionales de Información Financiera (NIIF), las Normas Internacionales de Auditoría (NIA), entre otras. En Colombia, el proceso de convergencia hacia estándares internacionales en contabilidad inició formalmente tras la expedición de la Ley 1314 de $2009^{2}$. Este proceso no solo plantea cambios en las tecnologías de cálculo, sino también en las racionalidades que respaldan estas

2 No obstante, el sector financiero colombiano ha sido pionero en el acercamiento a estándares contables internacionales, por medio de las obligaciones que surgen por cuenta de la regulación aplicada por la Superintendencia Financiera de Colombia. El precio justo de intercambio es un ejemplo de este acercamiento, pues es un método de valoración alineado con la lógica del valor razonable, de aplicación obligatoria para las entidades del sector financiero de acuerdo a lo establecido por el capítulo 1 de la Circular Básica Contable y Financiera de 1995. tecnologías y definen la forma como se comprende la realidad económica.

En el marco del proceso de evolución y estandarización experimentado por la contabilidad desde la década de 1970 hasta la actualidad, uno de los temas que han despertado especial interés en el ámbito organizacional ha sido el del cambio en los enfoques de valoración dominantes ${ }^{3}$. En este sentido, las tendencias internacionales han impulsado un desplazamiento desde un enfoque dinámico, que erige al costo histórico como principal método de valoración, hacia un enfoque estático, que consolida al valor razonable como el método de valoración más adecuado (Aglietta \& Rebérioux, 2009). Este desplazamiento ha favorecido una visión de empresa en la que prevalecen los objetivos de los inversionistas como agentes especuladores, antes que como propietarios.

Algunas situaciones en el ámbito contable como los cambios en los enfoques de valoración, adquieren una trascendencia significativa para las organizaciones, toda vez que el papel de la contabilidad no se circunscribe simplemente a una función técnica que da cuenta de las transacciones llevadas a cabo por una empresa durante un período determinado (Biondi, 2011; Cunningham, 2005; Ijiri, 1967). Por el contrario, de acuerdo a autores como Mauricio Gómez-Villegas (2004) y Shyam Sunder (2005), se puede asegurar que el papel de la disciplina contable se extiende a una labor de diseño y control sobre los contratos que conforman la

\footnotetext{
3 Este cambio ha sido liderado por países con mercados financieros altamente desarrollados, como Estados Unidos e Inglaterra, y se ha extendido a países de África, América Latina, Asia, Europa y Oceanía.
} 
organización, lo cual supone una relación de complementariedad con los modelos de gobierno corporativo (GC), cuya ocupación también se centra en la estructuración de las relaciones contractuales de la empresa en función de la eficiencia en el uso de los recursos.

La capacidad que tiene la contabilidad para reflejar, representar y construir la realidad ${ }^{4}$ (Ariza-Buenaventura, 2007), adquiere un rol central en la definición de las prácticas de control en las organizaciones. De esta forma, las características de la información contable, transmitida por los estados financieros y demás informes organizacionales ${ }^{5}$, responden a una serie de supuestos particulares que plantean cierta forma de interpretar la realidad e inciden en la idea que cada agente se forma sobre el cumplimiento de los acuerdos contractuales $y$, por tanto, en las prácticas de gobierno corporativo deseables para la consecución de sus objetivos.

Desde esta perspectiva, el estudio de las transformaciones experimentadas por la disciplina, la regulación y la práctica contable, desde el inicio del proceso de financiarización económica, puede enriquecer la comprensión de la evolución en las prácticas de gobierno corporativo en contextos específicos. No obstante, el presente documento se decanta por abordar,

4 Capacidad conocida como el poder constitutivo de la contabilidad (Ariza, 2007).

5 Los estados financieros (EE.FF.) constituyen solo una de las tantas vías de comunicación con que cuentan las organizaciones para transmitir la información financiera y no financiera, resultante de aplicar las prácticas contables. En este sentido, otras vías utilizadas por las organizaciones son, por ejemplo, los informes de gobierno corporativo, los informes de riesgo, los informes de responsabilidad social e, incluso, los comunicados de prensa. Lo anterior, sin contar la información informal que se encuentra en páginas web o en medios masivos de comunicación. principalmente, el papel de las prácticas contables a partir de los cambios en los métodos de valoración que trae la convergencia hacia las NIC y NIIF en Colombia.

En consecuencia, con el ánimo de profundizar en la naturaleza de la relación que emerge entre la contabilidad y el gobierno corporativo en el contexto colombiano, con énfasis en las prácticas de valoración contable, el documento ha sido estructurado en cuatro secciones, sin incluir la presente introducción. La primera sección presenta la teoría de la contabilidad y el control en las organizaciones como vía para analizar los vínculos entre contabilidad y gobierno corporativo. La segunda sección aborda la evolución de los enfoques de valoración en contabilidad y los modelos de gobierno de empresa. La tercera sección explora la relación de dependencia que resulta entre el valor razonable y el modelo de gobierno corporativo anglosajón y sus efectos en el contexto colombiano. La última sección presenta las conclusiones.

\section{Teoría de la contabilidad y el control en las organizaciones}

La teoría de la contabilidad y el control constituye una alternativa para la exploración y el análisis de las interacciones entre la contabilidad y el gobierno corporativo. De acuerdo con esta teoría, la contabilidad puede ser comprendida como una disciplina que brinda control, a partir de su capacidad para generar y proveer conocimiento común ${ }^{6}$ entre los diferentes

6 De acuerdo con Shyam Sunder, para que el conocimiento sea común se requiere que cada parte esté consciente de la observación del evento que hacen otros (Sunder, 2005). 
agentes vinculados a las organizaciones. Un conocimiento común que brinda control en la medida en que todos los agentes pueden estar pendientes de las condiciones contractuales de los demás y, a su vez, están conscientes de que los demás agentes se encuentran informados y pendientes de sus propias condiciones contractuales y de sus acciones, lo cual redunda en una disminución de costos por disputas a causa del diseño y control de algunos contratos (Sunder, 2005). De este modo, la contabilidad efectúa una labor de control en el sentido de asegurar la consecución de fines particulares ${ }^{7}$ de manera directa, toda vez que busca asegurar el cumplimiento de los fines y propósitos de los agentes y la sociedad, a partir de la eficiencia y eficacia en el uso de los recursos y la riqueza (Gómez, 2004).

Las bases de la teoría de la contabilidad y el control en las organizaciones se fundan en trabajos académicos que 1) reconocen la separación entre la propiedad y el control (Berle \& Means, 1932), 2) conciben la organización como un conjunto de acuerdos entre diversos factores de producción, en el cual cada agente es motivado por consideraciones personales, aunque no necesariamente egoístas (Kuznets, 1947), y 3) plantean que la incompletitud de la información en los contratos complejos da lugar a costos de resolución de disputas por cuenta de acciones oportunistas en entornos que dificultan el acceso al conocimiento común (Williamson, 2002).

A diferencia de la visión dominante de la teoría de la agencia, que plantea el problema de

7 Los fines de cada uno de los agentes interesados en la organización. la separación entre propiedad y control como un tema que involucra únicamente a los accionistas y a los gerentes, la visión de la teoría de la contabilidad y el control concibe un modelo contractual que amplía la consideración del principal al conjunto de stakeholders, de manera que actores como los proveedores, trabajadores y el gobierno se insertan como partes de interés legítimas en los procesos de gobernanza organizacional (San Jose \& Retolaza, 2012).

Esta visión contractual se fundamenta en la concepción holista de la organización planteada por Adolf Berle y Gardiner C. Means (1932), citados por Michel Aglietta y Antoine Rebérioux (2009), en el sentido de que "es conveniente... extender la responsabilidad de los dirigentes al conjunto de partes involucradas en la firma y no restringirla a la sola figura de los accionistas" (p. 51). Una visión que comparte elementos de análisis con la teoría institucional de la empresa de Paul Durand, Robert Edouard Jaussaud y André Vitu (1947) y Georges Ripert (1951), que resalta la importancia de la acción colectiva, y con aportes de Luigi Zingales (1998) y Margaret M. Blair y Lynn Stout (1999), quienes resaltan la importancia de que los deberes fiduciarios del administrador se ejerzan con relación al conjunto de la firma.

Así, el hecho de que el modelo contractual de la empresa reconozca la confluencia de intereses disímiles lleva a concebir la construcción de confianza como una vía adecuada para gestionar el correcto funcionamiento de la organización y el correspondiente cumplimiento de los objetivos de los actores (Gómez, 2004). En esta construcción de confianza, la contabilidad se erige como partícipe activo que incen- 
tiva la cooperación entre los actores, a partir de sus funciones básicas de medición, valoración y revelación. Específicamente, Shyam Sunder (2005) plantea cinco funciones por medio de las cuales la disciplina contable contribuye al ejercicio del control en las organizaciones, a saber: a) medir las contribuciones de todos los agentes, b) medir y distribuir los derechos de cada miembro, c) informar a los miembros sobre el grado de cumplimiento del contrato, d) distribuir información a los potenciales miembros y e) proveer cierta información como conocimiento común.

No obstante, más allá de la labor desempeñada por las prácticas contables en virtud del control en las organizaciones, es posible identificar otras fuentes de control organizacional que también participan en la construcción de la confianza como valor institucional. En este sentido, resalta el rol del gobierno corporativo, pues se encarga de "confeccionar normas e incentivos, contratos tácitos o explícitos, que alineen efectivamente el comportamiento de los agentes, con las pretensiones del principal, por medio de un reparto óptimo de los riesgos, bajo condiciones de incertidumbre" (Ana Isabel Fernández \& Silvia Gómez, 1999; Holmström, 1979; citados por Francisco Aníbal Ganga-Contreras \& José Ricardo Vera-Garnica, 2008).

De esta manera, el hecho de que tanto las prácticas de gobierno corporativo como las prácticas $^{8}$ contables se reconozcan como partícipes en la modelación de las relaciones con-

8 En este punto, cabe precisar la distinción entre los conceptos de gobierno corporativo y prácticas de gobierno corporativo. El primero, se refiere al régimen de mediación central entre los agentes que conforman la organización (Aglietta \& Rebérioux, 2009). El segundo, a los comporta- tractuales que conforman las organizaciones, supone una interacción directa entre ambas herramientas de control. Esta interacción forjada por la existencia de una función común exige un proceso de complementariedad dinámico, en el que convergen diferentes modelos de gobierno corporativo y diferentes enfoques de valoración en contabilidad.

Ante este escenario, es posible plantear que si eventuales cambios en las prácticas contables modifican la percepción de los actores sobre el cumplimiento de las relaciones contractuales en la organización, entonces, variarán las demandas que esos actores realizan sobre las prácticas de gobierno corporativo. La exigencia de prácticas eficientes de gobierno de empresa aumentará si las prácticas contables proveen una sensación de incertidumbre sobre el cumplimiento de los acuerdos contractuales. Por el contrario, las demandas se tornarán más laxas siempre y cuando las prácticas contables provean un ambiente de seguridad sobre el cumplimiento de los acuerdos contractuales.

El reconocimiento de la complementariedad que emerge entre contabilidad y gobierno corporativo permite advertir acerca de la necesidad de estudiar la racionalidad y las técnicas de cálculo contables para comprender los procesos de diseño y evolución de la gobernanza corporativa. Este estudio se torna complejo en la medida en que la contabilidad no es estática e inmutable; todo lo contrario, es dinámica y evolutiva, de modo que expande sus márgenes en función de las características que exhiben tiempos y lugares particulares (Miller, 1998; Power, 2010). Así, la forma como

mientos que deberían seguir los agentes organizacionales en función de objetivos particulares. 
la contabilidad adelanta los procesos de clasificación, medición, valoración y revelación puede variar de acuerdo a las tecnologías de cálculo y la racionalidad que las constituyan y, por lo tanto, puede incidir en la modelación de diversas demandas en términos de gobernanza empresarial.

En este sentido, los procesos de clasificación, medición, valoración y revelación se han estructurado, a partir de la evolución de la disciplina y la práctica contable. En lo que compete a la disciplina, esta evolución se caracteriza por la aproximación a la economía clásica, la teoría financiera, la teoría marginalista del valor, la estadística y la econometría, que en conjunto se alinean a una visión en la que la contabilidad no solo es útil para la toma de decisiones del inversionista individual, dada su facultad para representar idénticamente la realidad, sino que además, se comporta como un instrumento de medición del valor accionarial. En lo que concierne a la práctica contable, esta evolución se caracteriza por el respaldo a la posición de las finanzas como eje de desarrollo económico y organizacional contemporáneo, a partir de la redefinición de aspectos como las características cualitativas de la información financiera, los métodos de valoración, los usuarios de la información financiera, los conceptos de activo, pasivo e ingreso, entre otros.

Entre las transformaciones más significativas experimentadas por la contabilidad, en el marco de los procesos de adopción y/o convergencia hacia las NIIF, es preciso resaltar el desplazamiento en los enfoques de valoración dominantes. Estos enfoques revisten gran trascendencia en el desarrollo de las relaciones contractuales, toda vez que instrumentalizan supuestos económicos, organizacionales y financieros que definirán el valor de las transacciones en las que participa la empresa $y$, en consecuencia, el valor de las obligaciones y derechos de los diversos agentes organizacionales.

Con el ánimo de proveer mayor claridad acerca de la trascendencia que tienen los cambios en los enfoques de valoración contable, el presente documento resalta la manera en que esos enfoques responden a formas particulares de concebir la actividad empresarial. De este modo, se plantea que los cambios en los enfoques de valoración han coincidido con el tránsito en las concepciones del modelo de empresa dominante, desde una concepción según la cual la coordinación intrafirma constituye el elemento central, hacia una concepción en la cual la empresa pierde importancia como un todo y, en su lugar, se constituye en instrumento de valorización del patrimonio (Aglietta \& Rebérioux, 2009).

Ante esta perspectiva, y con el propósito de establecer un cuerpo conceptual que permita ilustrar los vínculos entre los enfoques de valoración contable y los modelos de gobierno de empresa, en la siguiente sección se buscará: 1) caracterizar los enfoques de valoración dominantes en contabilidad, 2) describir los modelos de gobierno de empresa más importantes en el ámbito internacional y 3) retratar algunas presiones que han privilegiado la aplicación del modelo de gobierno corporativo anglosajón en Colombia.

\section{Enfoques de valoración y modelos de empresa}

La naturaleza dinámica de la contabilidad se expresa, entre otros, por medio de la ampliación 
de sus márgenes, que se han redefinido históricamente conforme han cambiado las características de los contextos en los cuales se desarrolla. De esta manera, compartimos la idea expresada por Peter Miller (1998), según la cual “... la contabilidad es en sí misma un ensamblaje de dispositivos e ideas formadas en tiempos y lugares particulares, en lugar de un inmutable y universal punto de partida"9 (p. 608).

Los ejemplos más recurrentes que permiten representar la expansión de las fronteras de la contabilidad, se refieren a la transformación desde la teneduría de libros privada y la contabilidad legalista, en un contexto dominado por el mercantilismo, hacia la contabilidad de costos y de gestión, en un contexto dominado por la industrialización y, posteriormente, hacia la contabilidad financiera, en concordancia con contextos de capitalismo financiero y capitalismo financiarizado. Cada una de estas etapas de la contabilidad ha contribuido al desarrollo de una práctica contable que responde a las necesidades del contexto circundante (Anthony Hopwood, 1987, citado por Agudelo-Vargas, 2013), mediante un proceso de ampliación de fronteras en el cual los temas que en un momento dado están por fuera del campo de estudio, pueden constituir el centro de su desarrollo en otro momento (Miller, 1998).

Desde esta perspectiva, la comprensión de las condiciones en función de las cuales las márgenes de la contabilidad son alteradas puede proveer elementos que enriquecen los

9 Traducción propia. Texto original: “...that accounting is itself an ensemble of devices and ideas formed at particular times and in particular locales, rather than an immutable and universal starting point" (Miller, 1998, p. 608) procesos de análisis que buscan estudiar la incidencia de la disciplina contable sobre los esquemas organizacionales y sociales. Precisamente, el desplazamiento en los enfoques de valoración contable constituye una de las características más relevantes dentro de la ampliación de las márgenes de la contabilidad por cuenta de la financiarización económica. Desde la perspectiva de la contabilidad como práctica social e institucional, este desplazamiento no supone simplemente un cambio técnico sobre las tecnologías de cálculo. También involucra transformaciones, por lo menos, en dos sentidos: 1) las racionalidades que respaldan las prácticas contables y 2) la comprensión de la realidad económica que intenta representar la contabilidad (Chapman, Cooper \& Miller, 2009).

\subsection{Enfoques de valoración en contabilidad}

En contabilidad, se han introducido diversos métodos de valoración que buscan describir y proyectar cuantitativamente la circulación del ingreso y los agregados de riqueza (Mattessich, 1964). Cada uno de estos métodos descansa en supuestos que conciben de diversas maneras aquello que se pretende representar: la realidad. En consecuencia, con frecuencia, nos encontramos ante una multiplicidad de alternativas de valoración contable que permiten asignar diferentes valores cuantitativos a un mismo objeto y llevan a la discusión sobre la exactitud y pertinencia de cada uno de los métodos aplicados.

No obstante, la preferencia de un método de valoración sobre otro no se define por el hecho de que el primero sea más exacto que el 
segundo. Su preferencia está dada, más bien, por la correspondencia entre los conceptos constitutivos del método respecto a la racionalidad que define la realidad. De esta forma, las prácticas de valoración que respaldan supuestos preponderantes del contexto económico gozan de mayor aceptación que otras prácticas, dada su contribución a la captura, interiorización e instrumentalización de tales supuestos dentro del ámbito organizacional e institucional (Hopwood, 2000; Pardo, 2014). Así afirmamos, por ejemplo, que actualmente el valor razonable se prefiere sobre los demás métodos de valoración porque intenta representar la realidad, a partir de flujos de caja futuros, precios cotizados, mercados activos, volatilidades implícitas, diferenciales de crédito, entre otros conceptos, que constituyen el centro de desarrollo financiero contemporáneo al incidir en las decisiones de individuos y organizaciones vinculados directa e indirectamente a los mercados financieros (Gwilliam \& Jackson, 2008; Rayman, 2007; Zhang \& Andrew, 2014).

Autores como Michel Aglietta y Antoine Rebérioux (2009), Pablo Archel-Domench y Mauricio Gómez-Villegas (2014) y Christine Colette y Jacques Richard (2000) han vinculado los métodos de valoración contable a dos enfoques generales que responden a una visión particular de la empresa. Estos enfoques de valoración, conocidos como enfoque dinámico y enfoque estático, representan los extremos en medio de los cuales se ubican las cuestiones de valoración de los países occidentales (Aglietta \& Rebérioux, 2009).
El primero de estos enfoques de valoración se denomina enfoque dinámico, toda vez que busca captar la dinámica productiva de las organizaciones por el "aporte combinado de los activos para la generación del beneficio empresarial mediante el desarrollo de la actividad económica" (Archel \& Gómez, 2014, p. 107). La visión de este enfoque ubica la actividad empresarial como la racionalidad que dirige los procesos de valoración, en consecuencia, según Aglietta \& Rebérioux (2009), los métodos de valoración afines al enfoque dinámico suponen que:

$$
\begin{aligned}
& \text { (...) los elementos activados no tienen valor } \\
& \text { en sí sino solo en la medida en que partici- } \\
& \text { pan de la actividad de la empresa (...) (de } \\
& \text { manera que) una vez integrados a la entidad, } \\
& \text { los capitales físicos, los inmateriales y los fi- } \\
& \text { nancieros no pueden ver su valor variar sino } \\
& \text { solo por razones estrictamente ligadas a la } \\
& \text { actividad a la cual ellos contribuyen (p. 156). }
\end{aligned}
$$

Uno de los métodos de valoración que se identifica con el enfoque dinámico es el costo histórico, el cual responde a una visión productiva de la empresa, propia del capitalismo industrial y del gobierno de empresa continental europeo; de manera que aspectos como la medición de costos y la determinación del ingreso constituyen los principales temas de interés, a partir de una infraestructura de cálculo que alberga conceptos científicos y objetivos que buscan una normalización e individualización de la eficiencia (Miller, 1998).

El segundo de los enfoques de valoración, calificado como enfoque estático, tiene como 
objetivo "la maximización del valor del stock de inversiones para hacer frente a las expectativas de inversores y acreedores" (Archel \& Gómez, 2014, p. 107). La racionalidad que define el enfoque estático concibe la empresa como instrumento de valorización del patrimonio, de manera que los activos son valorados por el valor liquidable capaz de asegurar el reembolso al conjunto de las deudas de la compañía (Aglietta \& Rebérioux, 2009). La firma como un todo deja de existir y en su lugar es desintegrada en un conjunto de activos y pasivos sin conexión que cuentan con precios eficientes que los distinguen (Biondi, 2011).

El método de valoración que mejor expone la racionalidad del enfoque estático es el valor razonable. Este método se orienta en el inversor y en la gestión de los rendimientos de los activos, de manera consecuente con el capitalismo financiero y el gobierno de empresa anglosajón. En este escenario, el resultado empresarial ha perdido importancia en virtud de temas como la predicción del funcionamiento de los mercados, la formación de los precios o las tasas de retorno (Pardo, 2014).

El desplazamiento del enfoque dinámico al enfoque estático, en los enfoques de valoración dominantes en contabilidad, ha sido congruente con un contexto en el cual la rentabilidad sobre el capital financiero se ha convertido en el principal objetivo de las organizaciones que han recurrido a la gestión de activos en los mercados financieros para alcanzar tal objetivo. Así las cosas, la puesta en marcha de técnicas de valoración que apuntalen la gestión organizacional a procesos neoliberales, como el incremento de la acumulación de capital vía mercados financieros, emerge como una vía para introducir y legitimar conceptos y prácticas institucionales en el campo organizacional (Zhang \& Andrew, 2014).

De esta manera, la preferencia del valor razonable sobre el costo histórico personifica un cambio en el lenguaje de la información contable y financiera, en donde los datos que constituyen los flujos de información intentan exhibir mayor utilidad para la toma de decisiones de inversionistas, a partir de una preferencia de la relevancia sobre la confiabilidad (Biondi, 2011).

Sin embargo, más allá de disertar sobre los enfoques y modelos de valoración en contabilidad, es interés de este documento resaltar el vínculo entre estos enfoques y los modelos de gobierno de empresa. En consecuencia, en el siguiente apartado, se caracterizarán los modelos de gobierno de empresa más destacados en el ámbito internacional.

\subsection{Modelos de gobierno corporativo}

La definición de gobierno corporativo y las prácticas que se implementan para su ejecución pueden variar en función de la concepción de empresa a la cual se vincule. De esta manera, en el ámbito internacional existen diferentes concepciones de empresa y, por lo tanto, diversos modelos de gobierno corporativo, cada uno de los cuales representa estructuras particulares que intentan dirigir y controlar a las organizaciones para gestionar la consecución de objetivos particulares (Ganga \& Vera, 2008).

A pesar de que un buen número de definiciones de gobierno corporativo coincide en vincular el concepto a los sistemas de dirección y control que aplican en la empresa (Ben- 
goechea, 1996; Canals, 2004; OCDE, 2004; Tunzelmann, 2003), los objetivos que guían los procesos de dirección y control, y las herramientas que se instrumentalizan en tales procesos, marcan las diferencias más comunes en las perspectivas de gobierno de empresa.

De acuerdo con Andrei Shleifer y Robert W. Vishny (1997) y Michel Aglietta y Antoine Rebérioux (2009), los modelos de gobierno corporativo que resaltan en el plano internacional por su eficiente funcionamiento, son el modelo estadounidense o anglosajón, el modelo japonés o nipón y el modelo alemán o continental europeo; mientras que los países en desarrollo e incluso algunos países europeos como Italia se caracterizan por tener mecanismos de gobierno corporativo prácticamente inexistentes.

En atención a su importancia en el ámbito internacional, en especial en lo que respecta a su papel como punto de referencia en países con modelos de gobierno corporativo débiles o inexistentes, a continuación, se describen brevemente las características de los tres modelos referidos anteriormente:

- Modelo anglosajón: liderado por Estados Unidos y Reino Unido, el modelo de gobierno de empresa anglosajón se caracteriza por actuar sobre organizaciones con estructuras de capital desagregadas, en las que la principal fuente de financiación proviene de los mercados de capitales, en especial de los accionistas minoritarios e inversionistas institucionales. Así, otros actores vinculados a la organización — como los empleados, el gobierno o la administración-pierden im- portancia en la gobernanza institucional en virtud de los inversionistas.

Desde esta perspectiva, el gobierno de empresa se interesa fundamentalmente en garantizar que los inversionistas obtengan el retorno financiero de sus inversiones, al minimizar las posibilidades de que la administración participe en la fuga de fondos financieros (Hansmann \& Kraakman, 2000). En consecuencia, el modelo anglosajón plantea prácticas que garantizan la transparencia de la información, a partir de la gestión y solución de los problemas de agencia. Es decir, la separación entre la propiedad y el control, y los consecuentes problemas de riesgo moral y selección adversa entre el principal (inversionista) y el agente (administrador), fruto de la asimetría de la información, se convierten en los temas centrales tratados por las prácticas de gobierno corporativo (Meier \& Meier, 2014).

En este contexto, los estándares que generan obligaciones en materia de divulgación de información y transparencia financiera, el desarrollo de consejos de administración, comités de auditoría y comités de remuneración, y la concepción del mercado como fuente de control sobre las acciones de la administración, son elementos propios del modelo anglosajón (Ganga \& Vera, 2008). La visión de empresa desde la cual opera el modelo anglosajón exhibe rasgos semejantes a los de la visión de empresa con la cual se desarrolla el enfoque de valoración estático en contabilidad, toda vez que concibe 
la empresa como una fuente de valorización del patrimonio del inversionista.

- Modelo continental europeo: este modelo de gobierno de empresa se ha caracterizado históricamente por actuar sobre organizaciones que se distinguen por la concentración de la propiedad, el papel protagónico de los bancos en el financiamiento empresarial y el reconocimiento de la fuerza laboral como un actor central en los procesos de toma de decisiones (Aglietta \& Rebérioux, 2009; Hansmann \& Kraakman, 2000; Shleifer \& Vishny, 1997).

De esta manera, el modelo continental europeo brinda importantes derechos a los acreedores, al igual que el modelo anglosajón, pero débiles derechos a los accionistas minoritarios, lo que se traduce en debilidades en materia de transparencia financiera en los mercados de capitales. Por ejemplo, el sistema alemán, principal exponente del modelo continental europeo, privilegia los beneficios de los inversores permanentes, que comúnmente son los accionistas mayoritarios y entidades bancarias, por medio de condiciones de gobierno que: 1) garantizan el derecho al voto de los inversores permanentes en condiciones que les permiten incidir sobre las decisiones de la alta gerencia, 2) facilitan las adquisiciones como vía para la toma de control y 3) brindan herramientas para reemplazar con facilidad a los administradores (Shleifer \& Vishny, 1997).

En lo que respecta a la fuerza laboral, el modelo alemán se ha constituido en referente en materia de integración de trabajado- res a la estructura de gobierno corporativo como mecanismo que permite gestionar las ineficiencias y asimetrías de información producto de los contratos laborales (Hansmann \& Kraakman, 2000). En este sentido, se plantea el modelo de cogestión entre accionistas, asalariados y acreedores en el que los "representantes de asalariados tienen lugar en el consejo de vigilancia, al lado de representantes de los accionistas, elegidos en asamblea general" (Aglietta \& Rebérioux, 2009, p. 86).

- Modelo nipón: en lo que respecta al modelo de gobierno de empresa japonés, Andrei Shleifer y Robert W. Vishny (1997) resaltan la importancia de los bancos en los procesos de financiamiento de las organizaciones, mientras que Henry Hansmann y Reinier Kraakman (2000) destacan la participación del gobierno nacional como el actor encargado de garantizar que la acción empresarial sirva al interés público. En relación con los modelos de empresa estadounidense y alemán, el modelo nipón exhibe prácticas intermedias en la protección de los accionistas minoritarios; aunque al tiempo, muestra una clara convergencia al modelo continental europeo en la concepción holista de la empresa.

La incidencia del gobierno nacional sobre las prácticas de gobierno corporativo japonés, se presenta a partir de acciones enmarcadas dentro y fuera del derecho empresarial. Así, la disposición de burócratas del Estado sobre la asignación del crédito, licencias y normas anticompetitivas dibuja el conjunto de herramientas, 
comúnmente utilizadas, que desbordan el derecho empresarial. Por su parte, las normas que debilitan el control de los accionistas sobre los administradores hacen parte de las herramientas enmarcadas en el derecho de empresa (Hansmann \& Kraakman, 2000).

Ante la multiplicidad de modelos de gobierno corporativo, algunos autores han planteado la existencia de un proceso de convergencia internacional hacia el modelo anglosajón y resaltan que, conforme se desarrollen los mercados de capitales, la atracción ideológica y competitiva de este modelo será indiscutible (Ganga \& Vera, 2008; Hansmann \& Kraakman, 2000), mientras que otros autores, si bien han reconocido transformaciones en los modelos nipón y continental europeo, sostienen que no se puede aseverar que se trate de convergencia en la medida en que hay especificidades en cada modelo que se han fortalecido durante las últimas décadas ${ }^{10}$ (Aglietta \& Rebérioux, 2009). En todo caso, ambas posiciones coinciden en que el desarrollo de la esfera financiera ha actuado como dinamizador de una ideología anglosajona que promueve la protección al valor accionarial y, por tanto, la salvaguardia de los inversionistas-especuladores ${ }^{11}$,

10 De acuerdo a Aglietta \& Rebérioux (2009), algunas transformaciones experimentadas por el modelo continental europeo marcan divergencias o distanciamiento respecto al modelo anglosajón. Entre estas transformaciones, resaltan aquellas vinculadas a ofertas públicas, bloques de control y derecho social (participación de los trabajadores en procesos de información y consulta).

11 Los fondos de pensiones y fondos de inversión se erigen como los principales exponentes de la concentración del ahorro atomizado y, en consecuencia, como los principales representantes del ahorro de los nuevos inversionistas minoritarios (los trabajadores). a partir de prácticas corporativas que garanticen confianza y un discurso de transparencia en los mercados de capitales. La tabla 1 resume las características de los modelos de gobierno empresa, presentados en esta sección.

\subsection{Gobierno corporativo en Colombia}

La preponderancia ideológica del modelo de empresa anglosajón se ha reproducido en el contexto mundial con el apoyo de instituciones multilaterales como el Banco Mundial (BM), la Organización para la Cooperación y Desarrollo Económicos (OCDE) y el Banco Interamericano de Desarrollo (BID), entre otras, que legitiman e incentivan prácticas afines a una visión de gobierno corporativo que privilegia las condiciones en favor de la expansión de los mercados financieros, el ascenso del poder accionarial y el papel preponderante del inversionista.

Un ejemplo del respaldo que adelantan estas instituciones al modelo anglosajón se observa en las definiciones de gobierno corporativo que proveen. Al respecto, la Organización para la Cooperación y Desarrollo Económicos, OCDE (2004), asegura que el gobierno corporativo es comprendido como:
(...) un elemento clave para aumentar la efi- cacia económica y aumentar el crecimiento, así como para aumentar la confianza de los inversores (...) no se trata de una cuestión exclusivamente circunscrita a las relacio- nes entre los accionistas y el cuerpo directi- vo, aunque estas, de hecho, sean el elemento central (p. 12). 
PRÁCTICAS DE VALORACIÓN Y GOBIERNO CORPORATIVO / S. PARDO / 219

\begin{tabular}{|c|c|c|c|}
\hline \multirow[b]{2}{*}{ Características } & \multicolumn{3}{|c|}{ Principales modelos de gobierno corporativo } \\
\hline & Anglosajón & Continental europeo & Nipón \\
\hline Estructura de capital & Desagregada & Concentrada & Intermedia \\
\hline Fuentes de financiación & Mercados de capitales & $\begin{array}{l}\text { Acreedores (principalmente el } \\
\text { sector bancario) }\end{array}$ & $\begin{array}{l}\text { Sector bancario y mercado de } \\
\text { capitales }\end{array}$ \\
\hline Principales actores & $\begin{array}{l}\text { Accionistas minoritarios e } \\
\text { inversionistas institucionales }\end{array}$ & $\begin{array}{l}\text { Acreedores, trabajadores y } \\
\text { accionistas mayoritarios }\end{array}$ & Acreedores y Estado \\
\hline Objetivo & $\begin{array}{l}\text { Garantizar el retorno } \\
\text { financiero a inversionistas }\end{array}$ & $\begin{array}{l}\text { Fortalecer el papel de } \\
\text { los bancos, accionistas } \\
\text { mayoritarios y trabajadores } \\
\text { en la toma de decisiones de la } \\
\text { organización }\end{array}$ & $\begin{array}{l}\text { Garantizar el retorno a } \\
\text { inversionistas y fortalecer } \\
\text { el papel de los bancos y } \\
\text { accionistas mayoritarios en } \\
\text { la toma de decisiones de la } \\
\text { organización }\end{array}$ \\
\hline $\begin{array}{l}\text { Medios para alcanzar el } \\
\text { objetivo }\end{array}$ & Transparencia & Cogestión & $\begin{array}{l}\text { Transparencia y acción del } \\
\text { Estado }\end{array}$ \\
\hline $\begin{array}{l}\text { Enfoque de valoración } \\
\text { afín }\end{array}$ & Estático & Dinámico & Dinámico \\
\hline
\end{tabular}

Tabla 1. Características de los principales modelos de gobierno de empresa en el mundo Fuente: elaboración propia

El hecho de que una organización como la $\mathrm{OCDE}^{12}$ plantee de forma explícita una concepción del gobierno de empresa al servicio de los accionistas, constituye un precedente con enorme potencial de incidencia en la configuración de los modelos de gobierno de empresa nacionales, en particular en aquellos lugares que apenas están iniciando la definición de prácticas relativas al gobierno empresarial, como los países latinoamericanos.

De hecho, algunas instituciones de América Latina, distinguidas como referentes en la adopción de prácticas de gobierno corporativo, también han exhibido posiciones que privilegian los objetivos de los inversionistas sobre los objetivos de las demás partes interesadas, en sintonía con la perspectiva anglosajona. Tal es el caso de la

12 Con legitimidad internacional para abordar temas tan variados como administración pública, agricultura y alimentación, educación, desarrollo, empleo, medio ambiente y comercio, entre otros.
Corporación Andina de Fomento (CAF), la cual, en el documento diseñado para poner en consideración de las empresas de la región normas básicas de buen gobierno, indica que:

$$
\begin{aligned}
& \text { (...) se podría definir gobierno corporativo } \\
& \text { como el conjunto de prácticas, formales e } \\
& \text { informales, que gobiernan las relaciones en- } \\
& \text { tre los administradores y todos aquellos que } \\
& \text { invierten recursos en la empresa, principal- } \\
& \text { mente accionistas y acreedores (...) en es- } \\
& \text { tas circunstancias, unas buenas prácticas de } \\
& \text { gobierno corporativo son la clave para el ac- } \\
& \text { ceso de las empresas a los mercados de capital } \\
& \text { (CAF, 2005, p. 2). }
\end{aligned}
$$

En correspondencia con las posiciones de la OCDE y la CAF, los avances realizados en Colombia desde principios de la primera década del siglo XXI muestran una clara tendencia hacia la adopción y reproducción del discurso 
estadounidense. La resolución 275 de $2001^{13} y$ la Ley 964 de 2005, que constituyen la génesis normativa en materia de gobierno corporativo en Colombia (BID \& BVC, 2009; Gaitán, 2010), presentan una visión alineada con la defensa de los derechos de los accionistas y su trato equitativo como centro en las prácticas de gobernanza empresarial.

La resolución 275 de 2001 estableció la adopción de un código de gobierno corporativo para las empresas emisoras de valores interesadas en obtener financiación de los fondos de pensiones ${ }^{14}$. Este código debía incluir:

\section{(...) mecanismos para la protección del ac-} cionista minoritario, criterios de selección de los directivos y representantes legales, mecanismos para la revelación de información y los conflictos de interés, criterios de selección de vinculados comerciales, mecanismos de transparencia para la selección de revisor fiscal, y auditorías especializadas solicitadas por accionistas (BID \& BVC, 2009, p. 3).

Posteriormente, la Ley 964 de 2005 fortaleció la protección a los inversionistas mediante la obligatoriedad de comités de auditoría con miembros independientes y la revelación de los acuerdos de accionistas, entre otras medidas. En marzo de 2007, a partir de una iniciativa liderada por la Superintendencia Financiera, la Bolsa de Valores de Colombia y algunos gremios empresariales y financieros, se socializó

13 Emitida por la Superintendencia de Valores (desde 2005, Superintendencia Financiera, en la que se fusionaron las Superintendencias Bancaria y de Valores).

14 Principales inversionistas institucionales del país. el Código de Mejores Prácticas Corporativas ${ }^{15}$ que, a partir de una encuesta de obligatorio diligenciamiento para los emisores de valores, pretendía efectuar un mejor seguimiento y unificación de las prácticas de gobierno corporativo aplicadas por las organizaciones ( $\mathrm{Su}$ perintendencia Financiera, 2007).

El Documento conceptual de gobierno corporativo, emitido en agosto de 2010 por la Superintendencia Financiera, constituye un buen ejemplo que ilustra la alineación de los esfuerzos nacionales con la visión anglosajona de gobierno de empresa. Este documento define el buen gobierno corporativo como aquel sistema que proporciona mecanismos para que las decisiones adoptadas correspondan con los intereses de la entidad, sus accionistas y acreedores. Así mismo, resalta el papel central que supone el problema de teoría de la agencia y las tensiones que se derivan entre accionistas y administradores, accionistas mayoritarios y accionistas minoritarios, así como entre la sociedad y los grupos de interés.

De igual forma, es pertinente resaltar la Guía colombiana de gobierno corporativo para sociedades cerradas y de familia, presentada por la Superintendencia de Sociedades en septiembre de 2009. Esta guía constituye, posiblemente, el esfuerzo alternativo más importante que se ha planteado en materia de gobierno de empresa. Provee un conjunto de medidas que reconocen algunas particularidades de las empresas colombianas, que distan del típico modelo de empresa anglosajón, en especial en aspectos vinculados a la concentración de la propiedad y el papel de los accionistas mayoritarios y del sistema financiero local en la financiación de

15 También conocido como Código País. 
las actividades empresariales. No obstante, la guía reproduce la tendencia anglosajona de proporcionar herramientas que zanjan los conflictos entre el principal y el agente, lo cual invisibiliza a la mayoría de las partes interesadas en la organización.

Esta breve descripción de la evolución en la configuración de leyes e iniciativas que han definido el modelo de gobierno corporativo colombiano $^{16}$ (resumidas en el gráfico 1), resulta coherente e incluso legítima, si se analiza a la luz del sector que ha participado en su direccionamiento. Es decir, prácticas que garanticen una gobernanza empresarial en favor del valor accionarial y que busquen brindar confianza al inversionista especulador son coherentes para empresas que participan en los mercados de capitales y que, en consecuencia, aspiran a captar recursos de tales inversionistas. No obstante, la extensión de este enfoque a organizaciones con características distintas e, incluso, su aplicación en compañías listadas en bolsa con presencia significativa de actores diferentes a inversionistas, puede resultar inconveniente para el bienestar organizacional y social.

En este sentido, la ausencia de iniciativas regionales y nacionales que planteen un enfoque de gobierno de empresa acorde con la realidad organizacional dominante ${ }^{17}$ en Colombia,

16 En función de una perspectiva con características que buscan proteger los intereses de los accionistas e inversionistas, al tiempo que evitan hacer referencia explícita a grupos de interés como trabajadores, gobierno, clientes y medio ambiente, entre otros.

17 Una realidad organizacional caracterizada por la abundancia de micro, pequeñas y medianas empresas (mypime), que representan el 99,8\% del total de empresas del país y contribuyen en la generación del 70\% del empleo formal (Franco \& Urbano, 2010). Las mipyme además presentan promueve la adopción del referente de mayor visibilidad: el modelo de gobierno de empresa estadounidense; en especial cuando las entidades que promueven este referente, plantean sus bondades en favor de empresas no emisoras. Es el caso de la Corporación Financiera Internacional (IFC, por sus siglas en inglés) que, mediante el Manual IFC de gobierno de empresas familiares, traslada las prácticas de gobierno corporativo estadounidense a empresas que no cotizan en bolsa, bajo la premisa de que probablemente las pequeñas, medianas y grandes empresas familiares se interesarán en el futuro por cotizar en bolsas de valores como método para la obtención de recursos financieros. Es decir, se introduce una lógica en la que las prácticas de gobierno empresarial dejan de ser herramientas útiles para la gestión y control de la realidad organizacional y se convierten en herramientas útiles para la gestión y control de las expectativas organizacionales, muchas de las cuales son impuestas por la propia institucionalidad financiera.

De esta manera, se generan tendencias que amenazan con desconocer las características ${ }^{18}$

problemas de acceso a fuentes de financiación, por cuenta de la incipiente profundización de las entidades financieras (Zuleta, 2011) y las elevadas tasas de interés para este segmento del mercado. Por su parte, las grandes empresas se caracterizan por la elevada concentración de su capital, lo que coincide con un mercado de capitales en formación que, a febrero de 2015, albergaba tan solo 74 compañías en la Bolsa de Valores de Colombia (http://www.bvc.com.co/pps/tibco/ portalbvc/Home/Empresas/Listado+de+Emisores)

18 Entre las características a las que se hace referencia, resaltan: 1) dominancia de una estructura de propiedad familiar, 2) las principales fuentes de financiamiento provienen de préstamos bancarios y fuentes informales, 3) la formalización laboral emerge como desafío regional y 4) el sistema legal se caracteriza por la prescripción de normas que delimitan el funcionamiento de las organizaciones (Oehr \& Zimmermann, 2012). 
típicas de las empresas colombianas y socavar los objetivos de actores fundamentales en su devenir. Esta situación se ve reforzada por el proceso de convergencia hacia NIIF y la consecuente introducción acelerada del enfoque de valoración estático en el modelo contable del país.
Para dimensionar esta última situación, la próxima sección buscará profundizar las implicaciones organizacionales que supone para Colombia la construcción de un modelo de gobierno de empresa con perspectiva anglosajona en conjunto con la inserción del enfoque de valoración estático en contabilidad.

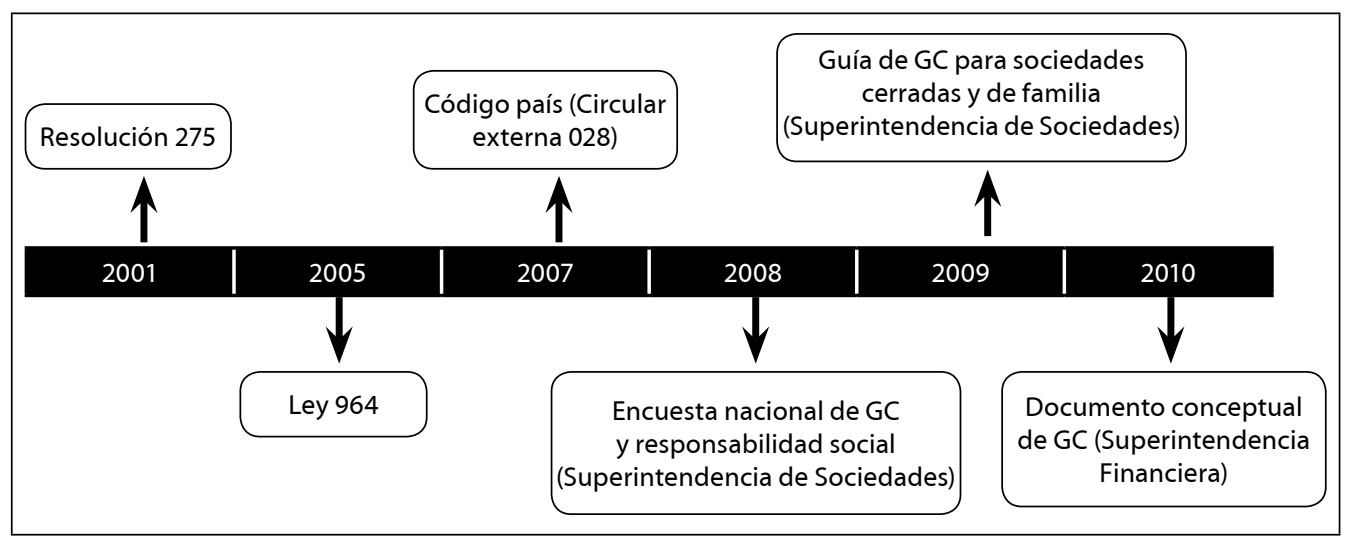

Gráfico 1. Avances de gobierno corporativo en Colombia (2000-2010)

Fuente: elaboración propia

\section{Valoración y gobierno corporativo}

Hasta este punto, la contabilidad ha sido presentada como una práctica social e institucional que contribuye al control en las organizaciones y que, en consecuencia, comparte un campo de acción con las prácticas de gobierno corporativo. De igual forma, se han caracterizado los cambios experimentados en las últimas décadas en: 1 ) los enfoques de valoración dominantes en contabilidad y 2) la consolidación internacional del enfoque de gobierno de empresa anglosajón, indicando que ambos procesos han sido introducidos en el contexto organizacional colombiano. El primero a partir de la convergencia hacia NIIF que incentivan el IASB, el FASB y el Financial
Stability Board (FSB). El segundo, por medio de iniciativas lideradas por organizaciones internacionales como la IFC, la OCDE y la CAF, y recogidas por instituciones financieras nacionales.

Ante este escenario, la presente sección resalta las coincidencias que surgen entre el valor razonable (principal exponente del enfoque de valoración estático) y el modelo de gobierno de empresa anglosajón, como herramientas de apropiación de un entorno institucional en el que las proyecciones y expectativas constituyen ejes de desarrollo económico. De igual forma, desde una óptica de control en las organizaciones, se resalta la inconveniencia que, para el contexto colombiano, genera la adopción plena de los estándares dominantes en contabilidad y gobierno de empresa. 


\subsection{Valor razonable y gobierno corporativo anglosajón}

El enfoque estático de valoración y el modelo de gobierno de empresa anglosajón comparten características que los convierten en representantes de una misma ideología: aquella del valor accionarial y la protección del inversionista individual, en la que la integración de la firma a la dinámica de los mercados financieros se convierte en elemento fundamental para el éxito empresarial (Aglietta \& Rebérioux, 2009). Su introducción al contexto colombiano no resulta extraña en la medida en que representa una visión de empresa, popularizada y, de cierta forma, admirada durante las últimas décadas por el mundo en general.

No obstante, el hecho de que la llegada del valor razonable y las prácticas de gobierno corporativo anglosajón constituyan una situación predecible, no implica que deban ser aceptadas sin discusiones y análisis críticos que aborden su pertinencia para el contexto colombiano; en especial, si se atiende a la importancia que estas prácticas adquieren en las relaciones de poder que enmarcan las organizaciones y el bienestar de los actores que las rodean.

En lo que compete a la contabilidad, las prácticas de valoración constituyen una de las principales vías de direccionamiento de las relaciones organizacionales (Biondi, 2011). En este sentido, el valor razonable legitima una racionalidad financiarizada que actúa como eje de desarrollo de las relaciones de poder en el plano organizacional. Los datos que proveen los informes financieros se convierten en insumos para la conducción de conductas y la preparación de probabilidades (Foucault, 1984) de los stakeholders en general, en favor de los intereses de inversionistas especuladores ${ }^{19}$. De esta forma, las prácticas de valoración dominantes convierten las expectativas y estimaciones en información "objetiva” que se combina con información real (histórica), transmitida por informes financieros y medios masivos de comunicación que repercuten en la comprensión que logran los stakeholders sobre la naturaleza de las transacciones organizacionales y legitiman la búsqueda de rendimientos en el corto plazo como objetivo central de los agentes.

Vemos así cómo los métodos de valoración tienen la capacidad de trascender la dimensión contable y afectar los procesos organizacionales vinculados al control de las relaciones entre agentes. En este sentido, los cambios en los métodos de valoración dominantes contribuyen a la resignificación del control, toda vez que el cumplimiento de los acuerdos contractuales deja de evaluarse en función de la actividad real o productiva y pasa a ser evaluado en función de la actividad especulativa (Archel \& Gómez, 2014). Se introducen condiciones en las que los contratos entre agentes se controlan con base en las dinámicas propias del capitalismo financiarizado $^{20}$.

De este modo, la preferencia del valor razonable sobre los demás métodos de valoración

19 Conducción de conductas en la medida en que los intereses de los inversionistas han sido objetivizados y legitimados por las técnicas de valoración contable, lo que permite que los demás actores organizacionales tomen como propios tales intereses.

20 El resultado empresarial pierde importancia en virtud de temas como la predicción del funcionamiento de los mercados, la formación de los precios, las tasas de retorno o las expectativas sobre beneficios futuros (Archel \& Gómez, 2014). 
contable promueve un contexto organizacional en el que la información financiera, además de limitar el balance y equilibrio entre los diferentes agentes, incentiva acciones de manipulación y explotación que afianzan la disparidad en las condiciones de negociación entre los agentes que tienen el control y los demás. Es decir, se presenta un debilitamiento del aporte de la contabilidad al control en las organizaciones en virtud de un fortalecimiento al control de las organizaciones, en beneficio de unos pocos agentes (inversionistas y acreedores), que logran imponer sus objetivos en las conductas y expectativas de la mayoría de los stakeholders.

Por su parte, las prácticas de gobierno corporativo que se han introducido en Colombia desde el sector financiero, han resaltado la importancia de cambios en la estructura de las empresas que garanticen la relevancia de la información y la defensa de los accionistas minoritarios. Sin embargo, han dejado de lado herramientas de gobernanza empresarial que exhiben modelos de empresa como el continental europeo y el nipón que permitirían incluir también la defensa de intereses de actores como trabajadores, proveedores, clientes, medio ambiente y Estado.

Es pertinente reconocer los límites del gobierno de empresa anglosajón para países con incipiente desarrollo en los mercados financieros, al tiempo que es recomendable evaluar las bondades de un modelo de empresa como el alemán para escenarios con una baja calidad de las condiciones laborales que actúa como barrera para el desarrollo económico y social del país.

$\mathrm{Al}$ respecto, no se pretende plantear que sea inconveniente desde cualquier perspectiva la aplicación del modelo de gobierno corporativo anglosajón; lo que se quiere esbozar es que si este permanece como el único modelo con respaldo institucional, se constituirá en el único punto de referencia de las empresas colombianas para implementar políticas de gobierno corporativo, y actuará como inductor en la relación empresas-mercados financieros en ambientes en los que el desarrollo empresarial está determinado más por la realización de actividades extractivas, productivas o de servicios que por actividades especulativas en mercados de capitales.

La adopción del modelo de gobierno corporativo anglosajón implica aceptar que el ideal de buen gobierno en las organizaciones está determinado por la generación de valor y el incremento constante de utilidades (Claessens \& Yurtoglu, 2013). Es aceptar que el buen gobierno se interesa por la defensa de comportamientos egoístas y competitivos que propenden por la acumulación de capital financiero, cuyas herramientas de control sobre el cumplimiento de los acuerdos contractuales prestarán su servicio a los poseedores de capital antes que a los demás agentes, renunciando así a la búsqueda de una convivencia justa entre los agentes organizacionales.

En síntesis, las prácticas de valoración y de gobierno corporativo, que han sido introducidas recientemente en Colombia, fundamentan su relevancia en una función instrumental, en la que sirven como medio para que el contexto organizacional acentúe el proceso de liberalización financiera, lo que incentiva un isomorfismo en el cual las economías en desarrollo buscan imitar los patrones económicos y financieros de las economías desarrolladas. 
En este escenario, las prácticas de valoración y gobierno de empresa han perdido importancia por su contribución al control de las relaciones contractuales en función de la eficiencia productiva. Ahora se consideran importantes siempre y cuando contribuyan al control de las relaciones contractuales en función de la eficiencia financiera.

\section{Conclusión}

El ascenso de las finanzas como principal vía de desarrollo económico, ha estado acompañado por una serie de cambios institucionales y organizacionales que proveen herramientas para la consolidación de las dinámicas de los mercados financieros en la realidad organizacional. Algunos de estos cambios se han gestado con la ayuda de disciplinas como la contabilidad y la administración, que han puesto a disposición de las finanzas herramientas como el valor razonable y las prácticas de gobierno corporativo anglosajón que legitiman e impulsan una lógica en favor del valor accionarial y la especulación.

A pesar de que hay diversas técnicas de valoración y diversos modelos de gobierno corporativo, la Arquitectura Financiera Internacional ha privilegiado las técnicas y modelos alineados con una visión estática de la empresa, en la cual la coordinación intrafirma pierde importancia, la empresa deja de ser vista como un todo y en su lugar se concibe como un constructo de activos generadores de liquidez para los poseedores del capital (Aglietta \& Rebérioux, 2009). Esta perspectiva ha sido impulsada, en parte, por los procesos de convergencia hacia estándares en contabilidad y gobierno corporativo que promueven instituciones como IASB, FASB y FSB, para los primeros, e IFC, FAC y OCDE, para los segundos.

No obstante, los procesos de convergencia hacia estándares en contabilidad y gobierno corporativo requieren escenarios de análisis y debate profundo que evalúen la pertinencia de sus prácticas en contextos que no cuentan con un entorno económico caracterizado por estructuras de capital desagregadas con mercados financieros altamente desarrollados. Un análisis que con frecuencia se evade, puesto que estas prácticas cada vez son más valoradas, por su labor instrumentalista, como medios que contribuyen a transformar las características económicas y financieras de los países en desarrollo, al acercarlos a escenarios en los que el crecimiento constante de la riqueza parece hacerse realidad con la acción de las finanzas y los mercados financieros.

La aplicación generalizada del valor razonable y de prácticas de gobierno corporativo de corte anglosajón en el contexto colombiano, supone privilegiar dinámicas especulativas que definen la empresa como una inversión encargada de generar valor y en la cual la información relevante es más importante que la información confiable, puesto que los inversionistas necesitan tomar decisiones con celeridad acerca del destino que deben brindar a sus excedentes de capital. Un escenario como este, en el cual resulta imperativo defender la posición de los poseedores del capital sobre las posiciones de los demás agentes, reforzará las condiciones de desigualdad ${ }^{21}$ que caracterizan el país,

21 El coeficiente de Gini del año 2012 ubica a Colombia con un puntaje de 53,5, en donde 0 significa equidad perfecta 
al brindar mayores herramientas de control y negociación organizacional a aquellos que ya las poseen e invisibilizar a otras partes como los trabajadores y los clientes ${ }^{22}$, cuyas conductas resultarán siendo conducidas hacia un débil ejercicio del control, por cuenta de: 1) información cuantitativa y cualitativa financiera con la capacidad de ocultar o resaltar la realidad en función de la racionalidad y los intereses inversionistas e 2) instrumentos de control corporativo incluyentes para los inversionistas y administradores, pero excluyentes para las demás partes de interés.

En este escenario, en Colombia, es de esperar que la aplicación de prácticas de valoración y de gobierno de empresa afines al modelo capitalista financiarizado insertarán mayor volatilidad al bienestar de los ciudadanos, a partir de la legitimación de escenarios en los que las estimaciones de transacciones futuras se confunden con hechos reales. De igual forma, estas prácticas aumentarán las tendencias de desigualdad y concentración de la riqueza por cuenta de: 1) la acentuación de una noción de control de las organizaciones en función de los intereses de los poseedores de capital y 2) la defensa del valor accionarial como medida de ingreso y desempeño empresarial que supone la

y 100 significa inequidad perfecta. De acuerdo a los datos del Banco Mundial, el puntaje de Colombia es el más alto (mayor desigualdad) entre los 34 países con información disponible para ese año y es el decimoquinto país más desigual del mundo, si se comparan las mediciones más recientes entre más de 160 países http://datos.bancomundial.org/indicador/SI.POV.GINI

22 Agentes como los trabajadores y los clientes se caracterizan por detentar una alta dispersión y variedad, que obstaculiza el planteamiento de posiciones consolidadas en el plano organizacional. distribución de riqueza a partir de nociones de ganancias no realizadas.

Por último, es conveniente precisar que la evaluación de los límites de los modelos de valoración y de gobierno de empresa y el análisis sobre la pertinencia de complementarlos con otras perspectivas más acordes a la realidad organizacional y social del país, se erigen como elementos de análisis que deben ganar protagonismo para nutrir los argumentos y dinamizar los procesos de diálogo social en los que deberían basarse decisiones de este estilo, con la capacidad de afectar el devenir organizacional, económico y social del país.

\section{Referencias}

Aglietta, Michel \& Rebérioux, Antoine (2009). El capitalismo financiero a la deriva. El debate sobre el gobierno de empresa. Bogotá: Universidad Externado de Colombia.

Agudelo-Vargas, María Victoria (2013). Análisis de los aportes de Anthony G. Hopwood a la disciplina contable. Lúmina, 14, 290-315. Disponible en: http://www.umanizales. edu.co/publicaciones/campos/economicas/ lumina/recursos/14/1.pdf

Archel-Domench, Pablo \& Gómez-Villegas, Mauricio (2014). Crisis de la valoración contable en el capitalismo cognitivo. Innovar, Revista de Ciencias Administrativas y Sociales, 24 (52), 103-116. Disponible en: http://www.revistas.unal.edu.co/index.php/ innovar/article/download/42526/44078 Ariza-Buenaventura, Efrén Danilo (2007). Luces y sombras en el poder constitutivo de la contabilidad ambiental. Investigación 
y Reflexión, 15 (2), 45-60. Disponible en: http://www.redalyc.org/pdf/909/90915204. pdf

Banco Interamericano de Desarrollo, BID \& Bolsa de Valores de Colombia, BVC (2009). Desarrollo de instrumentos informativos sobre mercados de capitales. Bogotá: Banco Interamericano de Desarrollo, BID \& Bolsa de Valores de Colombia, BVC.

Bengoechea-Goya, Juan (1996). El gobierno de empresas: características del debate actual. Situación: Revista de Coyuntura Económica, 3, 69-118, ejemplar dedicado a globalización y gobierno de empresas.

Berle, Adolf \& Means, Gardiner C. (1932). The Modern Corporation and Private Property. New York: MacMillan Company.

Biondi, Yuri (2011). The Pure Logic of Accounting: A Critique of the Fair Value Revolution. Accounting, Economics, and Law, 1 (1), 2-46. Disponible en: https:// halshs.archives-ouvertes.fr/hal-00561894/ document

Blair, Margaret M. \& Stout, Lynn (1999). A Team Production Theory of Corporate Law. Virginia Law Review, 85 (2), 247-328. Disponible en: http://business.illinois.edu/ josephm/BA549_Fall\%202014/Session\%20 4/4_Blair_Stout\%20\%281999\%29.pdf

Canals, Jordi (2004). Pautas del buen gobierno en los consejos de administración. Universia Business Review, 1, 18-27. Disponible en: http://www.redalyc.org/articulo. oa?id=43300102

Chapman, Christopher S.; Cooper, David J. \& Miller, Peter B. (2009). Linking Accounting, Organizations and Institutions. En
Christopher S. Chapman, David J. Cooper \& Peter Miller (eds.). Accounting, Organizations and Institutions. Essays in Honour of Anthony Hopwood, 1-29. Oxford: Oxford Scholarship Online.

Claessens, Stijn \& Yurtoglu, B. Burcin (2013). Corporate Governance in Emerging Markets. Emerging Markets Review, 15, 1-33.

Colette, Christine \& Richard, Jacques (2000). Comptabilité générale: les systèmes français et anglo-saxons. Paris: Dunod.

Colombia (2005). Ley 964 de 2005, del 8 de julio, por la cual se dictan normas generales y se señalan en ellas los objetivos y criterios a los cuales debe sujetarse el Gobierno Nacional para regular las actividades de manejo, aprovechamiento e inversión de recursos captados del público que se efectúen mediante valores y se dictan otras disposiciones. Disponible en: http:// www.alcaldiabogota.gov.co/sisjur/normas/ Norma1.jsp?i=22412

Colombia (2009). Ley 1314 de 2009, por la cual se regulan los principios y normas de contabilidad e información financiera y de aseguramiento de información aceptados en Colombia, se señalan las autoridades competentes, el procedimiento para su expedición y se determinan las entidades responsables de vigilar su cumplimiento. Disponible en: http://www.alcaldiabogota.gov.co/sisjur/ normas/Norma1.jsp?i=36833

Corporación Andina de Fomento, CAF (2005). Lineamientos para un Código Andino de Gobierno Corporativo. Eficiencia, equidad y transparencia en el manejo empresarial. CAF. 
Disponible en: http://www.caf.com/media/3266/linea6abril100dpi.pdf

Corporación Financiera Internacional, IFC (2010). Manual IFC de gobierno de empresas familiares. Disponible en: http:// documentos.bancomundial.org/curated/ es/2008/01/9784494/ifc-family-businessgovernance-handbook-manual-ifc-degobierno-de-empresas-familiares

Cunningham, Lawrence A. (2005). Finance Theory and Accounting Fraud: Fantastic Future versus Conservative Histories. $\mathrm{Bu}$ ffalo Law Review, 53, 789-814. Disponible en: http://lawdigitalcommons.bc.edu/cgi/ viewcontent.cgi ?article $=1121 \&$ context $=$ lsfp

Durand, Paul; Jaussaud, Robert Edouard \& Vitu, André (1947). Traité de droit du travail, 1947-1956. 4 vols. Paris: Dalloz.

Fernández, Ana Isabel \& Gómez, Silvia (1999). El gobierno de la empresa: mecanismos alineadores y supervisores de las actuaciones directivas. Revista Española de Financiación y Contabilidad, 28 (100), 355-380. Disponible en: http://www.aeca.es/pub/refc/acceso. php?id $=0227$

Foucault, Michel (1984). Cómo se ejerce el poder. 1-7. Disponible en: http:// www.unizar.es/deproyecto/programas/ docusocjur/FoucaultPoder.pdf

Franco-Ángel, Mónica \& Urbano-Pulido, David (2010). El éxito de la pyme en Colombia: Estudio de caso en el sector salud. Estudios Gerenciales, 26 (114), 77-97. Disponible en: http://www.icesi.edu.co/revistas/index.php/ estudios_gerenciales/article/view/332 Gaitán-Riaño, Sandra (2010). Gobierno corporativo en Colombia: tendencias actuales. Administer, 15, 137-153.

Disponible en: http://publicaciones.eafit. edu.co/index.php/administer/article/ download/207/258

Ganga-Contreras, Francisco Aníbal \& VeraGarnica, José Ricardo (2008). El gobierno corporativo: consideraciones y cimientos teóricos. Cuadernos de Administración, 21 (35), 93-126. Disponible en: http://www. scielo.org.co/pdf/cadm/v21n35/v21n35a05. pdf

Gómez-Villegas, Mauricio (2004). Una evaluación del enfoque de las Normas Internacionales de Información Financiera (NIIF) desde la teoría de la contabilidad y el control. Innovar, Revista de Ciencias Administrativas y Sociales, 14 (24), 112-131. Disponible en: http://www.redalyc.org/articulo. oa?id=81802409

Gómez-Villegas, Mauricio (2011). Pensando los fundamentos de la contabilidad como disciplina académica. Lúmina, 12, 120-150.

Gwilliam, David \& Jackson, Richard H. G. (2008). Fair Value in Financial Reporting: Problems and Pitfalls in Practice. A Case Study Analysis of the Use of Fair Valuation at Enron. Accounting Forum, 32 (3), 240-259.

Hansmann, Henry \& Kraakman, Reinier (2000). The End of History for Corporate Law. Harvard Law School John M. Olin Center for Law, Economic and Business Discussion Paper 280 Series, 1-34.

Holmström, Bengt (1979). Moral Hazard and Observability. Bell Journal of Economics, 10 (1), 74-91. Disponible en: http:// aida.econ.yale.edu/ dirkb/teach/pdf/ holmstrom/1979\%20moral\%20hazard.pdf 
Hopwood, Anthony (1987). The Archaeology of Accounting Systems. Accounting, Organizations and Society, 12 (3), 207-234.

Hopwood, Anthony G. (2000). Understanding Financial Accounting Practice. Accounting, Organizations and Society, 25 (8), 763-766. Disponible en: http://directory.umm.ac.id/ Data\%20Elmu/jurnal/A/Accounting, $\% 20$ Organizations\%20and\%20Society/Vol25. Issue8.Nov2000/3191.pdf

Ijiri, Yuri (1967). The Foundation of Accounting Measurement: A Mathematical, Economic and Behavioral Inquiry. Englewood Cliffs, New Jersey: Prentice-Hall.

International Accounting Standards Board, IASB (2010). El marco conceptual para la información financiera. IFRS Foundation. Disponible en: https://www.mef.gob. pe/contenidos/conta_publ/con_nor_ co/vigentes/niif/marco_conceptual_ financiera2014.pdf

Kuznets, Simon (1947). Measurement of Economic Growth. The Journal of Economic History, 7 (S1), 10-34.

Mattessich, Richard (2002). Contabilidad y métodos cualitativos. Buenos Aires: La Ley.

Meier, Heidi Hylton \& Meier, Natalie C. (2014). Corporate Governance: An Examination of US and European Models. Corporate Ownership \& Control, 11 (2), 347-351.

Miller, Peter (1998). The Margins of Accounting. The European Accounting Review, 7 (4), 605-621.

Oehr, Tim Frederik \& Zimmermann, Jochen (2012). Accounting and the Welfare State: The Missing Link. Critical Perspectives on Accounting, 23 (2), 134-152.
Organización para la Cooperación y Desarrollo Económicos, OCDE (2004). Principios de Gobierno Corporativo de la OCDE. París: Organización para la Cooperación y Desarrollo Económicos. Disponible en: http://www.oecd.org/daf/ca/ corporategovernanceprinciples/37191543. pdf

Pardo-López, Steven (2014). Transformaciones recientes de la disciplina contable desde una perspectiva social e institucional, capítulo 3. En Una evaluación de la relación de la disciplina contable y la evolución del sistema pensional colombiano, a partir de la ley 100 de 1993, 47-70. Tesis de maestría, Universidad Nacional de Colombia, Bogotá. Disponible en: http://www.bdigital.unal. edu.co/46657/1/08941016.2014.pdf

Pardo-López, Steven \& Peña-Cortés, Ángela Rocío (2012). Contabilidad y complejidad: la posibilidad de evolución y expansión de fronteras de la disciplina contable. XIII Asamblea General de la Asociación Latinoamericana de Facultades y Escuelas de Contaduría y Administración, ALAFEC, 9-12 de octubre de 2012. Buenos Aires, Argentina: ALAFEC. Disponible en: http://www.alafec.unam.mx/ memoria_xiii.php

Power, Michael (2010). Fair Value Accounting, Financial Economics and the Transformation of Reliability. Accounting and Business Research, 40 (3), 197-210. Disponible en: http://www.lse.ac.uk/ accounting/pdf/MKP\%20Accounting\%20 and\%20Business\%20Research\%20 \%283\%29.pdf 
Rayman, Robert Anthony (2007). Fair Value

Accounting and the Present Value Fallacy: The Need for an Alternative Conceptual Framework. The British Accounting Review, 39 (3), 211-225.

Ripert, Georges (1951). Aspects juridiques du capitalisme moderne. Paris: Librairie Générale de Droit de Jurisprudence, LGDJ.

San Jose Ruiz de Aguirre, Leire \& Retolaza, José Luis (2012). Participación de los stakeholders en la gobernanza corporativa: fundamentación ontológica y propuesta metodológica. Universitas Psychologica, 11 (2), 619-628. Disponible en: http://revistas. javeriana.edu.co/index.php/revPsycho/ article/download/1519/2227

Shleifer, Andrei \& Vishny, Robert W. (1997). A Survey of Corporate Governance. The Journal of Finance, 52 (2), 737-783. Disponible en: http://scholar.harvard.edu/files/shleifer/ files/surveycorpgov.pdf

Sunder, Shyam (2005). Introducción a la teoría de la contabilidad y el control. En Shyam Sunder. Teoría de la contabilidad y el control, 23-35. Bogotá: Universidad Nacional de Colombia, Facultad de Ciencias Económicas.

Superintendencia de Sociedades (2009). Guía colombiana de gobierno corporativo para sociedades cerradas y de familia. Disponible en: http://www.supersociedades.gov. co/inspeccion-vigilancia-y-control/ gobierno-corporativo-y-rse/cartillas-yguias/Cartillas\%20y\%20Guias/guia $\% 20$ colombiana $\% 20 \mathrm{de} \% 20$ gobierno $\% 20$ corporativo\%20\%288\%29.pdf

Superintendencia Financiera (1995). Circular Externa 100 de 1995, Circular Básica Con- table y Financiera. Disponible en: https:// www.superfinanciera.gov.co/jsp/loader.jsf?1 Servicio $=$ Publicaciones\&lTipo $=$ publicacio nes\&lFuncion $=$ loadContenidoPublicacion \&id $=15466$

Superintendencia Financiera (2001). Resolución 275, del 23 de mayo de 2001, por la cual se establecen los requisitos que deben acreditar las personas jurídicas públicas y privadas que pretendan ser destinatarias de la inversión de recursos de los fondos de pensiones. Disponible en: https://www.superfinanciera.gov.co/jsp/ loader.jsf?lServicio $=$ Publicaciones\&lTipo $=$ publicaciones\&lFuncion $=$ loadContenidoPu blicacion\&id $=821 \& d$ Print $=1$

Superintendencia Financiera (2007). Circular externa 028 de 2007: Código de Mejores Prácticas Corporativas, Colombia. Bogotá: Superintendencia Financiera. https://www. superfinanciera.gov.co/SFCant/Codigopais/ textos/codigopias.pdf

Superintendencia Financiera (2010). Documento conceptual de gobierno corporativo. Disponible en: https://www.superfinanciera. gov.co/SFCant/GobiernoCorporativo/ doccongb200810pub.pdf

Tunzelmann, Nick von (2003). Historical Coevolution of Governance and Technology in the Industrial Revolutions. Structural Change and Economic Dynamics, 14 (4), 365384. Disponible en: http://myweb.rollins. edu/tlairson/pek/coevolvetechins.pdf

Williamson, Oliver E. (2002). The Theory of the Firm as Governance Structure: from Choice to Contract. Journal of Economic Perspectives, 16 (3), 171-195. 
Disponible en: http://pubs.aeaweb.org/doi/ pdfplus/10.1257/089533002760278776

Zhang, Ying \& Andrew, Jane (2014). Financialisation and the Conceptual Framework. Critical Perspectives on Accounting, 25, 17-26, doi: 10.1016/j.cpa.2012.11.012

Zingales, Luigi (1998). Corporate Governance. En Peter Newman (ed.). The New Palgrave Dictionary of the Economics and the Law, 497-502. New York: MacMillan.

Zuleta, Luis Alberto (2011). Política pública $e$ instrumentos de financiamiento a las pymes en Colombia. Santiago de Chile: Organización de Naciones Unidas, Comisión Económica para América Latina y el Caribe, CEPAL, Documento de proyecto.
Disponible en: http://repositorio.cepal.org/ bitstream/handle/11362/3894/S2011060. pdf?sequence $=1$

- Fecha de recepción: 12 de diciembre de 2014

- Fecha de aceptación: 9 de abril de 2015

- Disponible en línea: 30 de abril de 2015

\section{Para citar este artículo}

Pardo-López, Steven (2015). Prácticas de valoración y gobierno corporativo: medios para la resignificación del control en las organizaciones colombianas. Cuadernos de Contabilidad, 16 (40), 205-231. http:// dx.doi.org/10.11144/Javeriana.cc16-40. pvgc 
